\title{
ISSFAL 2010 Dinner Debate: Healthy Fats for Healthy Hearts - Annotated Report of a Scientific Discussion
}

\author{
Joyce A. Nettleton ${ }^{a}$ Berthold Koletzko ${ }^{b}$ Gerard Hornstra ${ }^{c}$ \\ aScienceVoice Consulting, Denver, Colo., USA; ${ }^{b}$ Dr. von Hauner Children's Hospital, Ludwig Maximilian University, \\ Munich, Germany; ' Nutrition and Toxicology Research Institute, Maastricht University, Maastricht, The Netherlands
}

\section{Key Words}

Healthy fats $\cdot$ Heart disease $\cdot$ Saturates $\cdot$ Polyunsaturates $\cdot$

Omega- 6 polyunsaturates $\cdot$ Recommended omega- 6 intakes

\begin{abstract}
Background/Aims: The importance of reducing saturated fatty acid intake to prevent cardiovascular disease and recommended intakes for omega- 6 polyunsaturated fatty acids (PUFAs) are controversial. Therefore, experts debated these topics at the biennial meeting of the International Society for the Study of Fatty Acids and Lipids (ISSFAL), in May 2010. Methods: Debate transcripts, debaters' and discussants' reviews and literature citations were the basis of this report. Results: Participants agreed that saturates per se are not 'bad', but that dietary recommendations should emphasize the substitution of unsaturates for part of the saturates. Evidence supporting omega-6 PUFA intakes of 5 to $10 \%$ is mixed; some interpret the overall data from diverse studies as consistent with a reduction in the risk of cardiovascular mortality and events. Others assert that randomized controlled trial data suggest that higher intakes of omega- 6 PUFAs are not associated with lower risk of heart disease, or may even increase it. Conclusions: All agreed that a 5-year randomized controlled trial comparing the effects of historically low (2\%) with currently high (7.5\%) linoleic acid intakes
\end{abstract}

on cardiac endpoints would address the knowledge gap about the effects of different omega-6 PUFA intakes on the risk of heart disease.
A lively, impassioned debate about healthy fats for healthy hearts was held on May 31, 2010, in conjunction with the biennial meeting of the International Society for the Study of Fatty Acids and Lipids (ISSFAL), Maastricht, The Netherlands, from May 29 to June 2, 2010. The debate was organized for ISSFAL by the International Expert Movement (IEM), a group of experts committed to improving everyone's dietary fat quality. The activities of the IEM are funded by an unrestricted educational grant from Unilever NV under the auspices of the International Union of Nutritional Sciences.

The two-part debate, chaired by Prof. Berthold Koletzko, Ludwig Maximilian University, Germany, addressed the following propositions:

- reduction of saturated fat is an important element of dietary change in the primary prevention of coronary heart disease (CHD) at the population level;

- the consumption of at least $5-10 \%$ of energy from omega- 6 polyunsaturated fatty acids (PUFAs) reduces the risk of $\mathrm{CHD}$ relative to lower intakes.

\section{KARGER}

Fax +41613061234 E-Mail karger@karger.ch www.karger.com

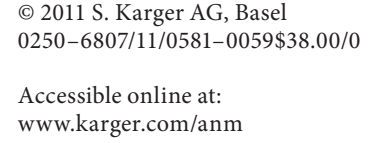

Joyce A. Nettleton, DSc

ScienceVoice Consulting

2931 Race Street

Denver, CO 80205 (USA)

Tel. +1 303296 9595, E-Mail sciencevoice@ q.com 
Discussing the first statement were Profs. Bruce German, University of California, USA, and Ricardo Uauy, University of Chile, Chile, and London School of Hygiene and Tropical Medicine, UK.

Opening the debate, Prof. German asserted that saturated fat is a 'highly functional fat', meaning that it is the most delicious, luxurious and pleasant sensation in one's mouth. As a result, saturated fats migrated into the food supply and changed the food supply itself. Saturated fat comes in different places, Prof. German said, the most obvious being lactation. For over 100 million years, mammalian mothers have produced milk with approximately $30 \%$ of total fatty acids as saturated fat, for the presumed benefit of their young [1]. This long-term conservation of saturated fatty acids in milk demonstrates the importance of saturated fats to the evolution of mammals, including humans [2]. What saturated fat is combined with today has much more influence on human health than saturated fat itself. Nonetheless, the question is: does consumption of bovine milk and dairy products result in increased levels of heart disease in the population? Prof. German then mentioned the work of Peter Elwood, who reported that saturated fats consumed as dairy are associated with a reduction in risk of ischemic heart disease, stroke, all-cause mortality and incident diabetes [3]. Saturated fat is not a toxin, Prof. German said. It functions as a signalling molecule that, unlike PUFAs, activates the synthesis of cholesterol and other lipids for the production of very-low-density lipoprotein particles, thereby providing fuel for physiological processes like exercise, lactation, infant growth and fighting infections [4-6]. This implies that saturated fat has a metabolic value. However, 50-year-old men who are sedentary, overweight, cannot lactate, do not exercise and have no infectious disease do not benefit from greater cholesterol synthesis and, therefore, may not be the appropriate reference point for dietary recommendations. Data show that saturated fat in a subset of the population can even be protective of heart disease [7]. Very high intakes of any substance, including saturated fat, are deleterious, moderate intakes mostly not. Prof. German concluded that dietary recommendations need to be based on the individual's need and on each person's metabolic response.

Prof. Uauy rebutted Prof. German's arguments by declaring that the discussion is not about ridding the diet of saturated fat because it is toxic. It is not. It was a mistake to recommend cutting down total fat intake. The discussion is about reducing one fat and replacing it with a healthier one. We often generalize about saturated fats, Prof. Uauy said, but we should understand that not all sat- urated fats are the same. For example, the biology of stearic acid is very different from that of the $\mathrm{C} 12, \mathrm{C} 14$, and $\mathrm{C} 16$ saturated fatty acids $[8,9]$. Foods contain a combination of fatty acids; milk might be good, something else not. We cannot lump all saturated fats together, but should be talking about reducing those saturated fats that raise the ratio of low- to high-density lipoproteins (LDL:HDL). The issue is complicated by different fat matrices and by trans fatty acids. The aim is not to lower total fat intake but to replace part of the dietary saturated fatty acids not with refined carbohydrate [10-12] nor with trans fatty acids [13] but with (poly)unsaturated fatty acids [14] that favorably affect the LDL:HDL cholesterol ratio, as supported by abundant evidence $[15,16]$. Prof. Uauy also highlighted results from Finland, which demonstrated that diet counselling of parents and their children was successful in reducing saturated fat intake and plasma cholesterol levels and improving additional cardiovascular risk markers [17].

In a brief reaction, Prof. German again challenged the view that saturated fats are bad; this would imply the public health assumption that the status quo - sedentary, overweight, inactive men - are the inexorable future of the human condition. Prof. German believes that we should aim for an 'active, playful society' where saturated fats 'in moderation, of course, will be an important part of every diet'.

Prof. Uauy responded that today's reality requires that we act now to fight obesity (which is on the rise) and $\mathrm{CHD}$, which is still the main killer. Increasing physical activity and replacing at least part of the cholesterol-raising saturates by (poly)unsaturates are essential changes we need to accept. 'Do what is best for most individuals', he said, and 'start early in life'.

A comment by Dr. Pedro Bastos, University of Lund, Sweden, noted that in some non-westernized populations myocardial infarction, stroke, metabolic syndrome and obesity are rare $[18,19]$. Yet these groups obtain about $17 \%$ of their calories from saturated fat [20]. We also have the Masai, Dr. Bastos continued, who rely for their nutrition mostly on milk, blood and meat and hence consume large amounts of saturated fat. Nonetheless, they have low serum cholesterol levels, and although they have coronary atherosclerosis their hearts are small and their coronary vessels actually enlarge with age, so that the lumina are not compromised by intimal thickening [21].

Prof. Uauy agreed that if we were as active as the Masai we wouldn't need to change our diet. But we are not. Until we change our physical inactivity, he repeated, we have to stay with the facts and replace at least part of the dietary saturates by (poly)unsaturates. 
Prof. Gerald Reaven, Stanford University, USA, noted that there are at least two major metabolic abnormalities that can lead to cardiac disease. One is an elevated plasma concentration of LDL cholesterol. This situation is controlled mostly by genes [22-24], with relatively modest ability to change by the amount or kind of fat [25]. Nonetheless, saturated fat reduction should be applied to lower LDL cholesterol, he added. In contrast, heart disease can also be based on a different metabolic abnormality characterized by insulin resistance, high insulin levels, high triglycerides and low HDL cholesterol concentrations. This is often the case in South Asian Indians [26-28]. In general, replacement of saturated fat by carbohydrate raises insulin and triglyceride concentrations and lowers HDL cholesterol levels [10, 12, 29]. Consequently, this will increase the risk of CHD. Prof. Reaven concluded that saturated fat replacement can contribute to lowering CHD risk, but the crucial question is: what does one replace it with? Replacement by carbohydrate is often not the best option.

Profs. German and Uauy fully agreed that genetics, diet and lifestyle should be the basis for recommendations to reduce cardiovascular risk. There is no reason to lower the dietary fat content, but the composition should be optimized, they concluded.

Dr. Apostolos Pappas, Johnson \& Johnson, USA, commented on the difficulty in making the right dietary recommendations because of lifestyle differences within the population. Vegetarians and vegans, for instance, can hardly be advised to lower their saturated fat intake because that intake is pretty low already [30,31]. Dr. Pappas advocated a focus on balancing the different types of dietary fats by using numerical ranges or ratios in dietary recommendations. The truth lies in the middle, he concluded, not in the extremes.

A final comment came from Prof. Birgitta Strandvik, Karolinska Institutet, Sweden, who described the absence of obesity and insulin resistance in the offspring of mice which were given a high saturated fat diet nearly free from essential fatty acids during pregnancy and lactation [32]. These results confirm the experience in former Scandinavian generations who had a very high saturated fat intake, but their children were usually not obese [33]. Referring to the work of Lands [34], Prof. Strandvik concluded that a high saturated fat intake together with small amounts of essential fatty acids might be preferred, especially during lactation.

Prof. William Harris, University of South Dakota, USA, and Dr. Christopher Ramsden, National Institutes of Health, USA, engaged the second proposition about consuming at least 5-10\% energy from omega-6 PUFAs to reduce the risk of CHD. The statement is based on a recent scientific advisory from the American Heart Association (AHA), published by Harris et al. [35]. The AHA examined different types of evidence in humans to assess the relationship between omega-6 PUFA intakes and cardiovascular disease. Studies included ecological and retrospective case-control studies, meta-analyses of randomized trials with physiologic measures of risk factors (blood lipoprotein levels), prospective cohort studies and randomized trials with clinical endpoints (myocardial events or cardiovascular deaths).

The ecological [36] and retrospective observational [37] data presented were consistent with the thesis that higher intakes of linoleic acid (LA) were associated with a lower risk of CHD. In the latter study [37], LA appeared to be an even more powerful predictor than eicosapentaenoic acid and docosahexaenoic acid. However, Prof. Harris emphasized that associations do not establish cause.

Of the studies providing stronger scientific evidence, Prof. Harris cited a meta-analysis of 60 randomized trials on omega-6 PUFA consumption and total, LDL, and HDL cholesterol levels. The greatest reduction in the ratio of total to HDL cholesterol was observed in those with the highest intakes of omega-6 PUFAs [38, 39]. Comparable results were obtained in a pooled analysis of 11 observational trials on incident CHD: for a 5\% lower energy intake from saturated fatty acids and a concomitant higher energy intake from PUFAs, there was a significant reduction in risk of coronary events and mortality [15].

A meta-analysis of randomized trials in which part of the saturated fatty acids was replaced by PUFAs reported a significant $19 \%$ pooled risk reduction in cardiovascular mortality and events with increased consumption of PUFAs from an average of 5\% to $15 \%$ energy [16]. It was recognized that fatty acid substitution or replacement studies cannot prove that the replaced fatty acid was responsible for the observed effect because what was replaced was also reduced. Prof. Harris finished by drawing attention to a recent narrative review from France, concluding that a recommended intake of omega-6 PUFAs above $5 \%$, and ideally about $10 \%$ of total energy, appears justified [40].

Challenging the AHA advisory, Dr. Ramsden cited the case of hormone replacement therapy (HRT) as an example of the potential hazards of basing recommendations on prospective cohort observational studies. HRT use has been consistently associated with reduced CHD risk in observational studies $[41,42]$. However, when this 
association was tested for causality in a randomized controlled trial, HRT caused substantial increases in risks of CHD and death $[43,44]$. Dr. Ramsden, therefore, concentrated his remarks on randomized controlled trials, which constitute the critical evidence base for the omega-6 PUFA recommendations, as also emphasized by Prof. Harris [45, 46].

Dr. Ramsden noted a shift in the AHA advisory from the non-specific term 'PUFA' when discussing randomized trials, to the more specific term 'omega- 6 PUFA' in making recommendations [35]. This imprecision in defining the terms 'PUFA' and 'omega-6 PUFA' overlooks the inclusion of omega-3 PUFAs. An extreme example of the contribution of omega-3 PUFAs to the total PUFA consumption is the Oslo Diet Heart Study [47, 48], which Dr. Ramsden described as 'a multiple-intervention trial masquerading as an omega-6 PUFA trial' because it had additional dietary changes.

He also noted that the meta-analysis of Mozaffarian et al. [16] contained 5 trials that were based on multiple interventions, including trans fatty acid replacement and increased omega-3 PUFA consumption. After eliminating those and including 2 additional studies not mentioned by Mozaffarian et al., 3 trials (4 data sets) specific to omega- 6 PUFAs were available [49-51]. A meta-analysis of these data demonstrated that higher intake of omega-6 PUFAs was associated with a 3-17\% greater risk of nonfatal myocardial infarction, cardiac death, or CHD risk and a nearly $16 \%$ higher risk of all-cause mortality ( $\mathrm{p} \geq 0.12$ ). From this analysis [52], Dr. Ramsden concluded that the consumption of 5-10\% omega-6-specific PUFAs does not reduce the risk of CHD.

Only one trial, the Lyon Diet Heart Study, examined the effect of consuming less than 5\% omega- 6 PUFAs [53]. As part of a multiple intervention to mimic the Mediterranean diet, LA consumption was reduced to less than $4 \%$ and $\alpha$-linolenic acid intake increased to $0.8 \%$. After a 27 -month follow-up, there was a $70 \%$ reduction in total mortality and a $73 \%$ reduction in total cardiac events in the treatment group [54]. This study 'unequivocally showed that high or moderate LA diets are not necessary for profound CHD risk reduction', Dr. Ramsden said.

He concluded that the available controlled trials produce no basis for population-wide recommendations to increase omega-6 PUFA consumption and stated that a randomized controlled trial comparing the effects of a low $(<2 \%)$ with a high $(>7 \%)$ LA diet on clinical CHD outcomes is 'long overdue'.

In response, Prof. Harris acknowledged that the randomized controlled trials discussed in the AHA advisory were not perfect; therefore, the committee relied on various types of evidence, some of which were not discussed so far. As an example, he mentioned that certain omega- 6 PUFAs give rise to some powerful vasodilatory, antiplatelet and anti-inflammatory compounds, e.g. lipoxins and prostacyclin. He noted that although controlled trials are not perfect, the totality of evidence supports the view that more omega-6 PUFAs are probably better than less. We don't know what's happening at a level of $2 \%$ LA, he added, but expressed doubt about the funding potentials of a trial to find out.

Dr. Ramsden noted that results from prospective cohort observational studies are extremely weak because they are often based on food frequency questionnaires. In his view, these questionnaires cannot reliably disentangle the respective intakes of LA and $\alpha$-linoleic acid. He urged the AHA to fund a randomized trial with a high oleic versus a high linoleic variety of sunflower or safflower oil with the same background diet.

Prof. Bill Lands (retired, National Institutes of Health, USA) strongly advised the scientific community to conduct scientific discussions only on the basis of data and facts and to maintain collegiality and openness although many fellow scientists compete for the same grants.

Dr. Bastos indicated that in India [55] and Israel [56] omega-6 PUFA consumption is very high and so is the rate of CHD. Of course, this does not show causality, he added, but it illustrates the need for a randomized controlled trial as suggested by Dr. Ramsden and supported by Prof. Harris.

Dr. Joe Hibbeln (National Institutes of Health, USA) referred to the work of Prof. Lands and others showing that reduction of dietary LA below $4 \%$ results in considerable increases in plasma or erythrocyte eicosapentaenoic acid or docosahexaenoic acid concentrations without additional intakes [57-59]. Dr. Ramsden later added that overabundant LA can also compete for esterification with other PUFAs, as illustrated by the nearly $50 \%$ reduction in arachidonic acid levels in coronary atheroma phospholipids obtained from subjects on a high (15\%) as compared to a low (4\%) linoleate diet in the LA Veterans Trial [60]. Similar conclusions regarding competition for esterification can be drawn from the negative correlation of LA with all highly unsaturated fatty acids in red-cell phospholipids of pregnant women [61].

Dr. Hibbeln also pointed out that humans evolved on a diet of $1-2 \%$ linoleate for five million years or more [62, 63]. Now we consume about $8 \%$ linoleate [64]. In mice, increasing the LA intake from 1 to $8 \%$ caused a doubling of the level of the endocannabinoid 2-arachidonoyl gly- 
cerol [65], which mediates increased food consumption and adiposity [66, 67]. If obesity predicts heart disease, Dr. Hibbeln added, one has to consider that the high-LA diets advocated by the AHA advisory may flood the brain, increase appetite and food intake, contribute to obesity and, ultimately, could promote heart disease.

Prof. Harris intervened that no significant relationship has yet been reported between LA intake and obesity in humans [68], but Dr. Ramsden responded that this is probably due to the saturation of all relevant enzymes at present LA intakes above $4 \%[69,70]$.

Dr. Peter Zock (Unilever, The Netherlands) supported Prof. Lands' appeal to stay with the facts. Although he considered Dr. Hibbeln's comment on linoleate and endocannabinoids inspirational, he felt they do not represent human data. He also expressed his admiration for the figures shown by Dr. Ramsden on the fatty acid compositions of the various trial diets, but based on his own experience with similar calculations he had to conclude that such figures are often guesses rather than facts. Dr. Ramsden responded by demonstrating that the disputed nutrient intakes in his figures were extracted from the published methods papers of the Oslo [48] and Lyon [53] Diet-Heart studies. Finally, when asked by Dr. Zock about the potential importance of omega- 6 PUFAs for reducing LDL cholesterol and, consequently, CHD risk, Dr. Ramsden replied that lowering LDL cholesterol sometimes lowers CHD [71, 72] and sometimes does not [73, 74]. He also stipulated that LDL cholesterol is just one factor involved in heart disease. The omega-3 index is another [75] and this index is reduced by dietary LA $[58,59]$. So, the most relevant health aspects of raising dietary linoleate above $5 \%$ are uncertain and become a matter of opinion rather than fact, Dr. Ramsden concluded.

Prof. Uauy noted an unsettled issue of great importance: the need for data comparing the effects of omega-3 PUFAs at varying backgrounds of omega- 6 PUFAs. Until there are new data to sort this out, we should be cautious in defining recommendations, he stated. There was also a suggestion from the floor that AHA withdraw its advisory statement, to which Prof. Harris responded that he was all for more data, but in his opinion AHA would be unlikely to withdraw the statement. The debate concluded with agreement by all that we need a randomized controlled trial to compare the effect of low and high intakes of LA. The trial should have typical US intakes of omega-3 PUFAs, with 7.5\% energy from LA (the current US intake) in one group and $2.0 \%$ LA (historical intake) in the other. It would study cardiac endpoints and continue for about 5 years.

\section{Disclosure Statement}

The authors each declare no conflict of interest in the participation in the ISSFAL debate or the preparation of this report. J.A.N. and G.H. received honoraria from the International Expert Movement through an unrestricted educational grant from Unilever NV, under the auspices of the International Union of Nutritional Sciences.

\section{References}

1 Blackburn DG: Lactation: historical patterns and potential for manipulation. J Dairy Sci 1993;76:3195-3212.

2 German JB, Dillard CJ: Saturated fats: a perspective from lactation and milk composition. Lipids 2010;45:915-923.

-3 Elwood PC, Pickering JE, Givens DI, Gallacher JE: The consumption of milk and dairy foods and the incidence of vascular disease and diabetes: an overview of the evidence. Lipids 2010;45:925-939.

4 Lin J, Yang R, Tarr PT, Wu PH, Handschin C, Li S, Yang W, Pei L, Uldry M, Tontonoz P, Newgard CB, Spiegelman BM: Hyperlipidemic effects of dietary saturated fats mediated through PGC- $1 \beta$ coactivation of SREBP. Cell 2005;120:261-273.

5 Magkos F: Basal very low-density lipoprotein metabolism in response to exercise: mechanisms of hypotriacylglycerolemia. Prog Lipid Res 2009;48:171-190.
6 Rohas LM, St-Pierre J, Uldry M, Jager S Handschin C, Spiegelman BM: A fundamental system of cellular energy homeostasis regulated by PGC-1 $\alpha$. Proc Natl Acad Sci USA 2007;104:7933-7938.

7 Mozaffarian D, Rimm EB, Herrington DM: Dietary fats, carbohydrate, and progression of coronary atherosclerosis in postmenopausal women. Am J Clin Nutr 2004;80: 1175-1184.

$>8$ Keys A, Anderson JT, Grande F: Serum cholesterol response to changes in the diet. IV. Particular saturated fatty acids in the diet. Metabolism 1965;14:776-787.

9 Hegsted DM, McGandy RB, Myers ML, Stare FJ: Quantitative effects of dietary fat on serum cholesterol in man. Am J Clin Nutr 1965;17:281-295.
10 Siri PW, Krauss RM: Influence of dietary carbohydrate and fat on LDL and HDL particle distributions. Curr Atheroscler Rep 2005;7:455-459.

$\checkmark 11$ Jakobsen MU, Dethlefsen C, Joensen AM, Stegger J, Tjonneland A, Schmidt EB, Overvad K: Intake of carbohydrates compared with intake of saturated fatty acids and risk of myocardial infarction: importance of the glycemic index. Am J Clin Nutr 2010;91: 1764-1768.

12 Parks EJ, Hellerstein MK: Carbohydrate-induced hypertriacylglycerolemia: historical perspective and review of biological mechanisms. Am J Clin Nutr 2000;71:412-433.

13 Teegala SM, Willett WC, Mozaffarian D: Consumption and health effects of trans fatty acids: a review. J AOAC Int 2009;92:12501257. 
-14 Siri-Tarino PW, Sun Q, Hu FB, Krauss RM: 23 Chang MH, Yesupriya A, Ned RM, Mueller Saturated fatty acids and risk of coronary heart disease: modulation by replacement nutrients. Curr Atheroscler Rep 2010;12: 384-390.

- 15 Jakobsen MU, O’Reilly EJ, Heitmann BL, Pereira MA, Balter K, Fraser GE, Goldbourt U, Hallmans G, Knekt P, Liu S, Pietinen P, Spiegelman D, Stevens J, Virtamo J, Willett WC, Ascherio A: Major types of dietary fat and risk of coronary heart disease: a pooled analysis of 11 cohort studies. Am J Clin Nutr 2009;89:1425-1432.

-16 Mozaffarian D, Micha R, Wallace S: Effects on coronary heart disease of increasing polyunsaturated fat in place of saturated fat: a systematic review and meta-analysis of randomized controlled trials. PLoS Med 2010; 7:e1000252.

-17 Niinikoski H, Lagstrom H, Jokinen E, Siltala M, Ronnemaa T, Viikari J, Raitakari OT, Jula A, Marniemi J, Nanto-Salonen K, Simell O: Impact of repeated dietary counseling between infancy and 14 years of age on dietary intakes and serum lipids and lipoproteins: The STRIP study. Circulation 2007;116: 1032-1040.

18 Lindeberg S, Lundh B: Apparent absence of stroke and ischaemic heart disease in a traditional Melanesian island: a clinical study in Kitava. J Intern Med 1993;233:269-275.

-19 Lindeberg S, Eliasson M, Lindahl B, Ahren B: Low serum insulin in traditional Pacific Islanders - the Kitava study. Metabolism 1999;48:1216-1219.

-20 Lindeberg S, Nilsson-Ehle P, Terent A, Vessby B, Schersten B: Cardiovascular risk factors in a Melanesian population apparently free from stroke and ischaemic heart disease: the Kitava study. J Intern Med 1994;236:331340 .

-21 Mann GV, Spoerry A, Gray M, Jarashow D: Atherosclerosis in the Masai. Am J Epidemiol 1972;95:26-37.

-22 Waterworth DM, Ricketts SL, Song K, Chen L, Zhao JH, Ripatti S, Aulchenko YS, Zhang W, Yuan X, Lim N, Luan J, Ashford S, Wheeler E, Young EH, Hadley D, Thompson JR, Braund PS, Johnson T, Struchalin M, Surakka I, Luben R, Khaw KT, Rodwell SA, Loos RJ, Boekholdt SM, Inouye M, Deloukas P, Elliott P, Schlessinger D, Sanna S, Scuteri A, Jackson A, Mohlke KL, Tuomilehto J, Roberts R, Stewart A, Kesaniemi YA, Mahley RW, Grundy SM, McArdle W, Cardon L, Waeber G, Vollenweider P, Chambers JC, Boehnke M, Abecasis GR, Salomaa V, Jarvelin MR, Ruokonen A, Barroso I, Epstein SE, Hakonarson HH, Rader DJ, Reilly MP, Witteman JC, Hall AS, Samani NJ, Strachan DP, Barter P, van Duijn CM, Kooner JS, Peltonen L, Wareham NJ, McPherson R, Mooser V, Sandhu MS: Genetic variants influencing circulating lipid levels and risk of coronary artery disease. Arterioscler Thromb Vasc Biol 2010;30:2264-2276.
PW, Dowling NF: Genetic variants associated with fasting blood lipids in the US. Population: Third National Health and Nutrition Examination Survey. BMC Med Genet 2010; 11:62.

24 Yoshida T, Kato K, Yokoi K, Oguri M, Watanabe S, Metoki N, Yoshida H, Satoh K, Aoyagi Y, Nozawa Y, Yamada Y: Association of genetic variants with myocardial infarction in japanese individuals with different lipid profiles. Int J Mol Med 2010;25:607-616.

-25 Kraemer FB, Greenfield M, Tobey TA, Reaven GM: Effects of moderate increases in dietary polyunsaturated:saturated fat on plasma triglyceride and cholesterol levels in man. Br J Nutr 1982;47:259-266.

$\checkmark 26$ Laws A, Jeppesen JL, Maheux PC, Schaaf P, Chen YD, Reaven GM: Resistance to insulinstimulated glucose uptake and dyslipidemia in Asian Indians. Arterioscler Thromb 1994; 14:917-922.

27 Palaniappan LP, Kwan AC, Abbasi F, Lamendola C, McLaughlin TL, Reaven GM: Lipoprotein abnormalities are associated with insulin resistance in South Asian Indian women. Metabolism 2007;56:899-904.

28 Gupta R, Joshi P, Mohan V, Reddy KS, Yusuf S: Epidemiology and causation of coronary heart disease and stroke in India. Heart 2008;94:16-26.

29 Siri-Tarino PW, Sun Q, Hu FB, Krauss RM: Saturated fat, carbohydrate, and cardiovascular disease. Am J Clin Nutr 2010;91:502509.

30 Craig WJ: Health effects of vegan diets. Am J Clin Nutr 2009;89:1627S-1633S.

31 Craig WJ, Mangels AR: Position of the American Dietetic Association: vegetarian diets. J Am Diet Assoc 2009;109:1266-1282.

-32 Palsdottir V, Wickman A, Andersson N, Hezaveh R, Olsson B, Gabrielsson BG, Strandvik B: Postnatal deficiency of essential fatty acids in mice results in resistance to diet-induced obesity and low plasma insulin during adulthood. Prostaglandins Leukot Essent Fatty Acids 2011; 84:85-92.

33 Hellström N (ed): A Social Hygienic Investigation in the Counties of Västerbotten and Norrbotten. Lund, Håkan Ohlsson, 1934.

34 Lands B: A critique of paradoxes in current advice on dietary lipids. Prog Lipid Res 2008; 47:77-106

35 Harris WS, Mozaffarian D, Rimm E, KrisEtherton P, Rudel LL, Appel LJ, Engler MM, Engler MB, Sacks F: Omega- 6 fatty acids and risk for cardiovascular disease. A science advisory from the American Heart Association Nutrition Subcommittee of the Council on Nutrition, Physical Activity, and Metabolism; Council on Cardiovascular Nursing; and Council on Epidemiology and Prevention. Circulation 2009;119:902-907.

36 Roberts DC: Dietary factors in the fall in coronary heart disease mortality. Prostaglandins Leukot Essent Fatty Acids 1991;44:97101.
37 Block RC, Harris WS, Reid KJ, Spertus JA: Omega- 6 and trans fatty acids in blood cell membranes: a risk factor for acute coronary syndromes? Am Heart J 2008;156:11171123.

-38 Mensink RP, Zock PL, Kester AD, Katan MB: Effects of dietary fatty acids and carbohydrates on the ratio of serum total to HDL cholesterol and on serum lipids and apolipoproteins: a meta-analysis of 60 controlled trials. Am J Clin Nutr 2003;77:1146-1155.

-39 Micha R, Mozaffarian D: Saturated fat and cardiometabolic risk factors, coronary heart disease, stroke, and diabetes: a fresh look at the evidence. Lipids 2010;45:893-905.

40 Czernichow S, Thomas D, Bruckert E: n-6 fatty acids and cardiovascular health: a review of the evidence for dietary intake recommendations. Br J Nutr 2010;104:788-796.

41 Stampfer MJ, Colditz GA: Estrogen replacement therapy and coronary heart disease: a quantitative assessment of the epidemiologic evidence. Prev Med 1991;20:47-63.

42 Grodstein F, Stampfer MJ, Manson JE, Colditz GA, Willett WC, Rosner B, Speizer FE, Hennekens $\mathrm{CH}$ : Postmenopausal estrogen and progestin use and the risk of cardiovascular disease. N Engl J Med 1996;335:453461.

43 Grodstein F: Invited commentary: can selection bias explain the cardiovascular benefits of estrogen replacement therapy? Am J Epidemiol 1996;143:979-982; discussion 983984.

$\checkmark 44$ Nelson HD, Humphrey LL, Nygren P, Teutsch SM, Allan JD: Postmenopausal hormone replacement therapy: scientific review. JAMA 2002;288:872-881.

45 Kris-Etherton P, Fleming J, Harris WS: The debate about $n-6$ polyunsaturated fatty acid recommendations for cardiovascular health. J Am Diet Assoc 2010;110:201-204.

46 Kris-Etherton P, Harris WS: Dietary omega- 6 polyunsaturated fatty acids - important for heart health. Clin Nutr Insight 2009;35: $1-5$.

$\checkmark 47$ Leren P: The Oslo diet-heart study. Elevenyear report. Circulation 1970;42:935-942.

48 Leren P: The effect of plasma cholesterol lowering diet in male survivors of myocardial infarction. A controlled clinical trial. Acta Med Scand Suppl 1966;466:1-92.

49 Rose GA, Thomson WB, Williams RT: Corn oil in treatment of ischaemic heart disease. Br Med J 1965;1:1531-1533.

50 Frantz ID Jr, Dawson EA, Ashman PL, Gatewood LC, Bartsch GE, Kuba K, Brewer ER: Test of effect of lipid lowering by diet on cardiovascular risk. The Minnesota Coronary Survey. Arteriosclerosis 1989;9:129-135.

51 Woodhill JM, Palmer AJ, Leelarthaepin B, McGilchrist C, Blacket RB: Low fat, low cholesterol diet in secondary prevention of coronary heart disease. Adv Exp Med Biol 1978; 109:317-330. 
-52 Ramsden CE, Hibbeln JR, Majchrzak SF, Davis JM: n-6 fatty acid-specific and mixed polyunsaturate dietary interventions have different effects on CHD risk: a meta-analysis of randomised controlled trials. Br J Nutr 2010;104:1586-1600.

53 de Lorgeril M, Renaud S, Mamelle N, Salen P, Martin JL, Monjaud I, Guidollet J, Touboul P, Delaye J: Mediterranean $\alpha$-linolenic acidrich diet in secondary prevention of coronary heart disease. Lancet 1994;343:14541459.

54 de Lorgeril M, Salen P, Martin JL, Monjaud I, Delaye J, Mamelle N: Mediterranean diet, traditional risk factors, and the rate of cardiovascular complications after myocardial infarction: final report of the Lyon Diet Heart Study. Circulation 1999;99:779-785.

55 Pella D, Dubnov G, Singh RB, Sharma R, Berry EM, Manor O: Effects of an IndoMediterranean diet on the omega-6/omega-3 ratio in patients at high risk of coronary artery disease: the Indian paradox. World Rev Nutr Diet 2003;92:74-80.

56 Dubnov G, Berry EM: Omega-6/omega-3 fatty acid ratio: the Israeli paradox. World Rev Nutr Diet 2003;92:81-91.

-57 Hibbeln JR, Nieminen LR, Blasbalg TL, Riggs JA, Lands WE: Healthy intakes of n-3 and $n-6$ fatty acids: estimations considering worldwide diversity. Am J Clin Nutr 2006;83: 1483S-1493S

58 Clark KJ, Makrides M, Neumann MA, Gibson RA: Determination of the optimal ratio of linoleic acid to alpha-linolenic acid in infant formulas. J Pediatr 1992;120:S151-S158.
59 Munakata M, Nishikawa M, Togashi N, Nio E, Kobayashi Y, Omura K, Haginoya K, Tanaka S, Abe T, Hishinuma T, Chida N, Tsuchiya S, Onuma A: The nutrient formula containing eicosapentaenoic acid and docosahexaenoic acid benefits the fatty acid status of patients receiving long-term enteral nutrition. Tohoku J Exp Med 2009;217:2328

60 Dayton S, Hashimoto S, Pearce ML: Influence of a diet high in unsaturated fat upon composition of arterial tissue and atheromata in man. Circulation 1965;32:911-924.

61 Friesen RW, Innis SM: Linoleic acid is associated with lower long-chain n-6 and n-3 fatty acids in red blood cell lipids of Canadian pregnant women. Am J Clin Nutr 2010;91: 23-31.

62 Eaton SB, Eaton SB 3rd, Sinclair AJ, Cordain L, Mann NJ: Dietary intake of long-chain polyunsaturated fatty acids during the paleolithic. World Rev Nutr Diet 1998;83:1223.

63 Kuipers RS, Luxwolda MF, Dijck-Brouwer DA, Eaton SB, Crawford MA, Cordain L, Muskiet FA: Estimated macronutrient and fatty acid intakes from an East African Paleolithic diet. Br J Nutr 2010;104:1666-1687.

64 Ervin RB, Wright JD, Wang CY, KennedyStephenson J: Dietary intake of fats and fatty acids for the United States population: 19992000. Adv Data 2004;1-6.

65 Alveheim A O-HD, Robert P, Madsen L, Kristiansen K, Frøyland L, Hibbeln J: Dietary Linoleic Acid Promotes Hypereactive Hepatic 2-Arachidonoyl-Glycerol And Contributes to Diet-Induced Obesity. Maastricht, International Society for the Study of Fatty Acids and Lipids, 2010, p 106.

-66 Andre A, Gonthier MP: The endocannabinoid system: its roles in energy balance and potential as a target for obesity treatment. Int J Biochem Cell Biol 2010;42:1788-1801.

67 Massa F, Mancini G, Schmidt H, Steindel F, Mackie K, Angioni C, Oliet SH, Geisslinger G, Lutz B: Alterations in the hippocampa endocannabinoid system in diet-induced obese mice. J Neurosci 2010;30:6273-6281.
68 Field AE, Willett WC, Lissner L, Colditz GA: Dietary fat and weight gain among women in the Nurses' Health Study. Obesity (Silver Spring) 2007;15:967-976.

69 Mohrhauer H, Holman RT: The effect of dose level of essential fatty acids upon fatty acid composition of the rat liver. J Lipid Res 1963;4:151-159.

70 Holman RT: The slow discovery of the importance of omega 3 essential fatty acids in human health. J Nutr 1998;128:427S-433S.

71 Randomised trial of cholesterol lowering in 4,444 patients with coronary heart disease: the Scandinavian Simvastatin Survival Study (4S). Lancet 1994;344:1383-1389.

72 Buchwald H, Campos CT, Boen JR, Nguyen PA, Williams SE: Disease-free intervals after partial ileal bypass in patients with coronary heart disease and hypercholesterolemia: report from the Program on the Surgical Control of the Hyperlipidemias (POSCH). J Am Coll Cardiol 1995;26:351-357.

73 Rossebo AB, Pedersen TR, Boman K, Brudi P, Chambers JB, Egstrup K, Gerdts E, Gohlke-Barwolf C, Holme I, Kesaniemi YA, Malbecq W, Nienaber CA, Ray S, Skjaerpe T, Wachtell K, Willenheimer R: Intensive lipid lowering with simvastatin and ezetimibe in aortic stenosis. N Engl J Med 2008;359:13431356

74 Tavazzi L, Maggioni AP, Marchioli R, Barlera S, Franzosi MG, Latini R, Lucci D, Nicolosi GL, Porcu M, Tognoni G: Effect of rosuvastatin in patients with chronic heart failure (the GISSI-HF trial): A randomised, doubleblind, placebo-controlled trial. Lancet 2008; 372:1231-1239.

75 Harris WS: The omega-3 index as a risk factor for coronary heart disease. Am J Clin Nutr 2008;87:1997S-2002S. 